\title{
EKSPLORASI DENAH RUMAH TINGGAL DI LAHAN MAGERSARI
}

\author{
Ronim Azizah \\ Program Studi Arsitektur, Fakultas Teknik, Universitas Muhammadiyah Surakarta \\ Jl. A. Yani Tromol Pos 1 Pabelan Kartasura 57102 Telp 0271717417 \\ ronimazizah@gmail.com
}

\begin{abstract}
ABSTRAK. Dengan semakin tingginya harga lahan di perkotaan serta tingkat pendapatan penduduk yang berbeda-beda maka membangun rumah dengan cara magersari menjadi sebuah pilihan. Rumah magersari menggunakan lahan secara bersama oleh keluarga ataupun orang lain dimana lahan terbagi menjadi beberapa petak untuk dibangun beberapa rumah tinggal. Rumah magersari juga memiliki fasilitas umum yang digunakan secara komunal berupa MCK (mandi, cuci, kakus), infrastruktur dan akses jalan. Kondisi ini menjadi lebih efektif jika dibandingkan dengan membeli lahan baru dengan harga yang sangat tinggi. Pengembangan atau perubahan desain rumah mungkin saja terjadi sehingga perlu digali sejauhmana pengembangan desain rumah tinggal yang dibangun pada lahan magersari dengan mempertimbangkan keberadaan fasilitas komunal. Pencarian data menggunakan metode survei dan pembahasan dilakukan dengan studi pustaka yaitu: (1) sumbersumber dari dokumen tekstual; (2) sumber-sumber dari dokumen gambar; dan (3) sumber-sumber dari dokumen artefaknya. Pada akhir pembahasan, menghasilkan simpulan yang menjelaskan bahwa tata ruang desain rumah magersari mampu mengintegrasikan zona ruang-ruang privat (rumah inti) dan zona ruang publik (fasilitas komunal).
\end{abstract}

Kata kunci: rumah, magersari, pengembangan rumah

ABSTRAK. Recently, to build a house by using "magersari" method has became an appropriate choice because of the economic condition of the community and refer to the high price of the land. Magersari house is a method by using the land together within family or other people. The method is by dividing the land into some blocks of land which will contain a small house for each block. This magersari house will provide public facilities which will be used communally such as MCK (Mandi, Cuci, Kakus), infrastructure and access for pedestrians and vehicles. This condition become effectively if compare by buying new land with high price. The development and transformation of the house design could be happened, thus it will be a necessary to explore how extend to which the development will continue within magersari house by considering the existence of communal facilities. Collecting data will be conducted by survey method and the analysis will be completed by exploring literature study: (1) textual document sources; (2) figure document sources; (3) artefact document sources. For final discussion, it will be concluded by explaining about how extend to which the layout of the magersari house design could integrate all private space zones (main space) and public space zones (communal facilities) within magersari house.

Keywords: house, magersari, house development

\section{PENDAHULUAN}

Suatu kota atau kabupaten dikatakan mengalami perkembangan yang baik jika kondisi bangunan yang ada berupa permukiman, sarana pendidikan, perkantoran, kesehatan dan bangunan umum lainnya berada dalam kondisi yang baik dan lalu lintasnya padat. Hal ini juga ditunjang dengan tingkat kepadatan penduduk yang tinggi baik penduduk lokal maupun pendatang. Pesatnya perkembangan kota dan peningkatan jumlah penduduk maka akan memicu permintaan lahan untuk perkantoran, perdagangan, permukiman dan bangunan umum lainnya.

Wilayah perkotaan pada umumnya telah didominasi oleh lahan untuk permukiman, sehingga permasalahan rumah tetap menjadi isu yang strategis pada masa-masa mendatang. Saat ini pembangunan rumahrumah di perkotaan tidak bisa lagi menggunakan model-model tradisional, yang umumnya membutuhkan tanah yang luas dan bangunan yang besar. Harga tanah maupun bangunan di perkotaan sudah sangat mahal, sehingga dibutuhkan biaya yang sangat tinggi dalam suatu pembangunan rumah jika masih menggunakan model tradisional Selain harga lahan yang mahal juga dipicu oleh tingkat pendapatan dan jenis pekerjaan penduduk yang beragam sehingga akan beragam pula daya beli penduduk terhadap lahan. Dengan kondisi tersebut maka di perkotaan mulai bermunculan rumah magersari dimana sebuah lahan digunakan secara bersama-sama oleh 
beberapa keluarga dengan sistim hak guna lahan. Namun ada juga rumah magersari yang digunakan secara bersama oleh penghuni non keluarga (penyewa lahan).

Menurut Ikaputra (dalam Winarna, 2005) rumah magersari yang terletak di kampung maka disebut Kampung Magersari dimana tuan tanah dapat menyewakan lahan berukuran kecil kepada penyewa yang disebut "pengindung". Tanggungjawab penyewa adalah menjaga lahan dan infrastruktur, merawat tanaman dan pepohonan serta melindungi lahan dari para pendatang ilegal. Menurut Winarna (2005), rumah magersari merupakan perumahan tradisional dan permukiman yang mengitari Kraton Yogyakarta pada jaman dulu. Konsep magersari dapat diaplikasikan untuk perkembangan perumahan dan permukiman pada masa sekarang. Dengan konsep magersari maka penghuni dengan pendapatan rendah dan menengah dapat hidup berdampingan di lahan yang sama, terjadi interaksi yang baik antar penghuni dan fasilitas infrastruktur menjadi lebih efisien sehingga tercipta lingkungan yang baik. [1]

Perancangan rumah secara umum menyediakan tiga fasilitas yang sangat penting agar rumah dapat dihuni yaitu ruang tamu, kamar tidur dan dapur sedangkan sarana servis dapat disediakan pada tahapan selanjutnya. Pada kondisi lahan yang terbatas maka perancang harus mampu merekayasa desain agar kebutuhan utama/ primer dapat terpenuhi dan kebutuhan sekunder minimal dapat disediakan supaya dapat melengkapi kebutuhan primer. Selain kondisi lahan yang terbatas karakter lingkungan sekitar juga menjadi faktor pendukung disain. Perumahan modern memiliki fasilitas tempat tinggal dan infrastruktur yang memadai sedangkan pada rumah magersari fasilitas infrastruktur tidak memadai dan masing-masing rumah tidak memiliki MCK pribadi. Oleh karenanya perlu digali proses merancang rumah tinggal yang berada di lahan magersari dimana faktor kebersamaan harus dilestarikan.

\section{PEMBAHASAN}

Untuk melakukan eksplorasi disain rumah magersari maka dilakukan tiga tahap proses yaitu (1) survei data yaitu mendata kondisi eksisting rumah magersari; (2) studi referensi yang terkait dengan konsep pengembangan bentuk dan (3) perancangan.
Lokasi yang di teliti merupakan sebuah lahan milik keluarga Bapak Rozan yang terletak di Kelurahan Gayam Kabupaten Sukoharjo. Berikut ini peta lokasi rumah magersari:

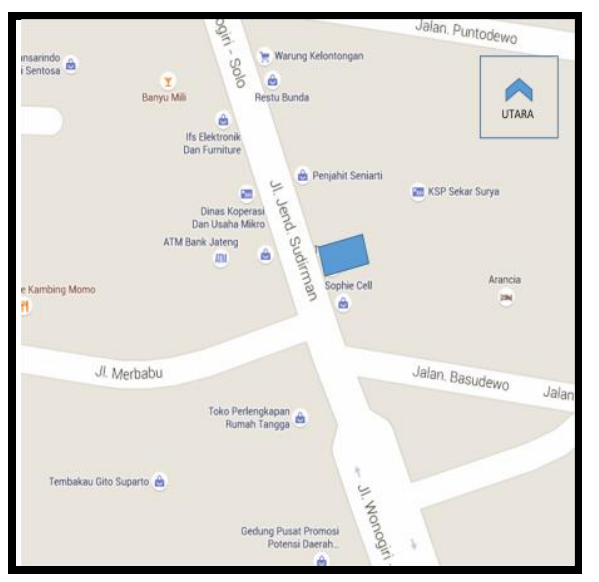

Gambar 1. Peta Lokasi Rumah Magersari http://www.google.go.id/maps/place/sukoharjo [2]

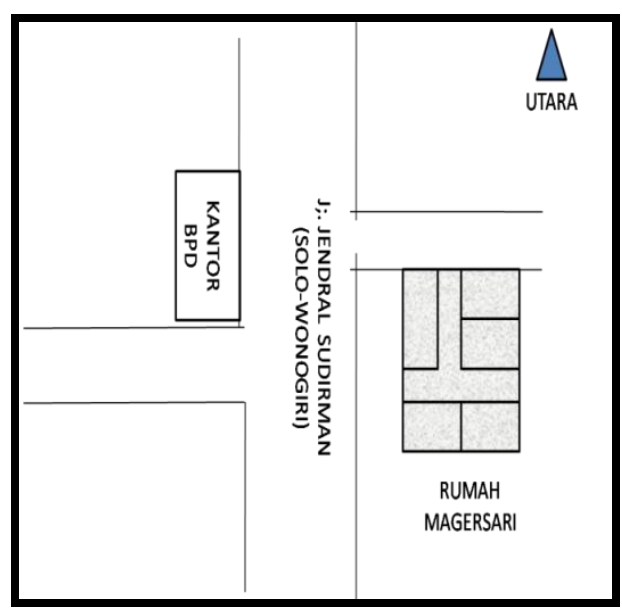

Gambar 2. Lokasi Rumah Magesari Sumber: Survei, 2015

Lahan seluas $\pm 598 \mathrm{~m}^{2}$ merupakan lahan milik keluarga Bapak Rozan yang telah dibagi untuk kelima anaknya menjadi lima petak lahan dengan luas masing-masing petak $7 \times 13 \mathrm{~m}^{2}$. Fasilitas yang disediakan untuk digunakan secara bersama adalah jalan selebar $2 \mathrm{~m}$, area jemuran dan tiga unit km/ wc. Pada rumah no. 3 merupakan rumah yang terdapat fasilitas bersama berupa sumur dan km/ wc bersama sedangkan rumah no.1, 2, 4 dan 5 tidak memiliki km/ wc pribadi. 


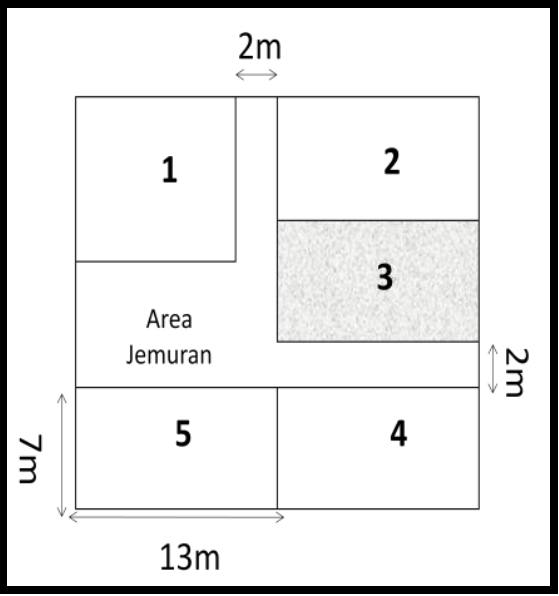

Gambar 3. Site Plan Rumah Magersari Sumber: Survei 2015

\section{KONDISI EKSISTING}

Pada denah eksiting terdapat ruang inti berupa ruang tamu, kamar tidur, $\mathrm{km} / \mathrm{wc}$ dan dapur sedangkan ruang servis beberapa ruang yang tersedia antara lain: sumur, 3 kamar mandi dan gudang yang digunakan secara bersama. Berikut gambar denah eksiting rumah no.3:

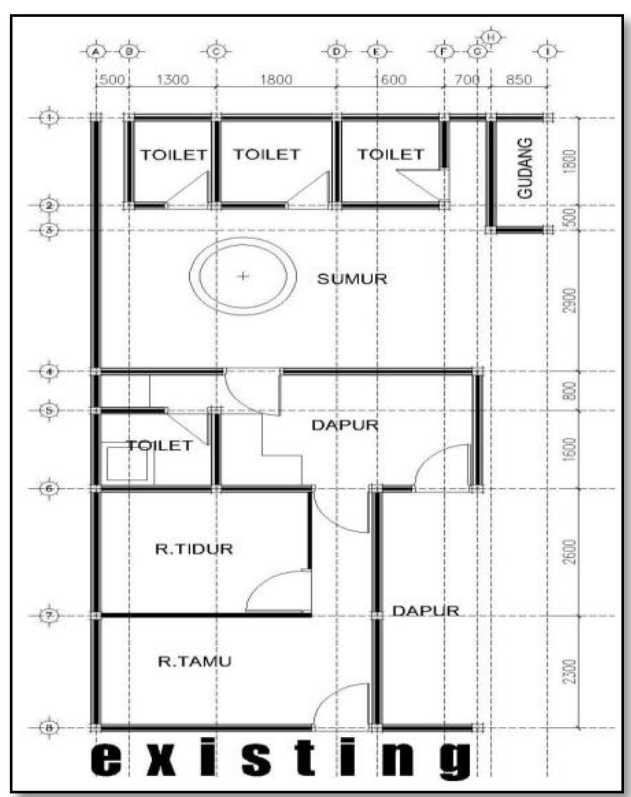

Gambar 4. Denah Eksisting Rumah no. 3 Sumber: Dokumen Penulis, 2015

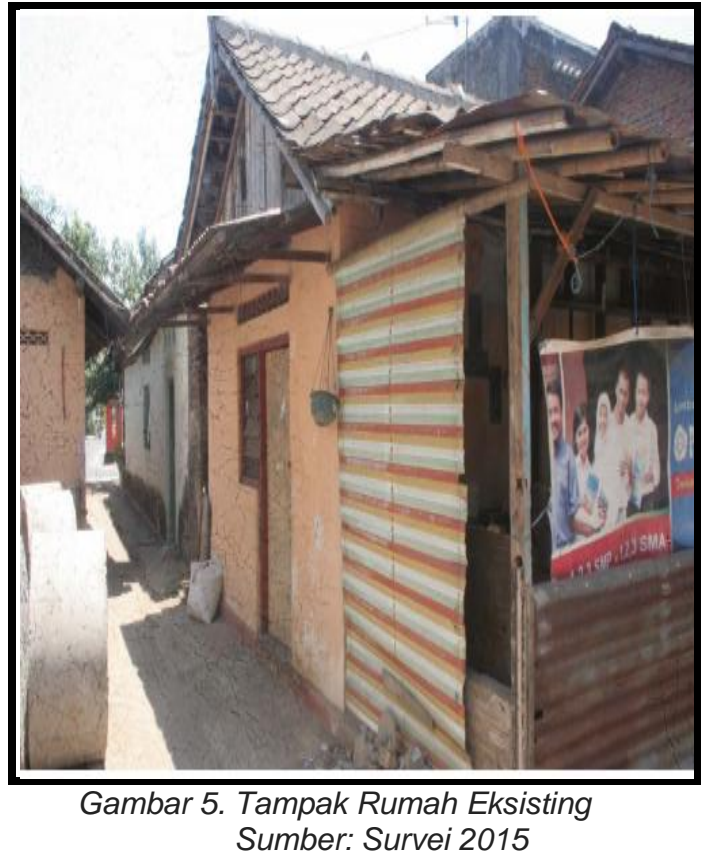

Pembagian area rumah tinggal dan fasilitas bersama dapat dilihat pada gambar dibawah ini:

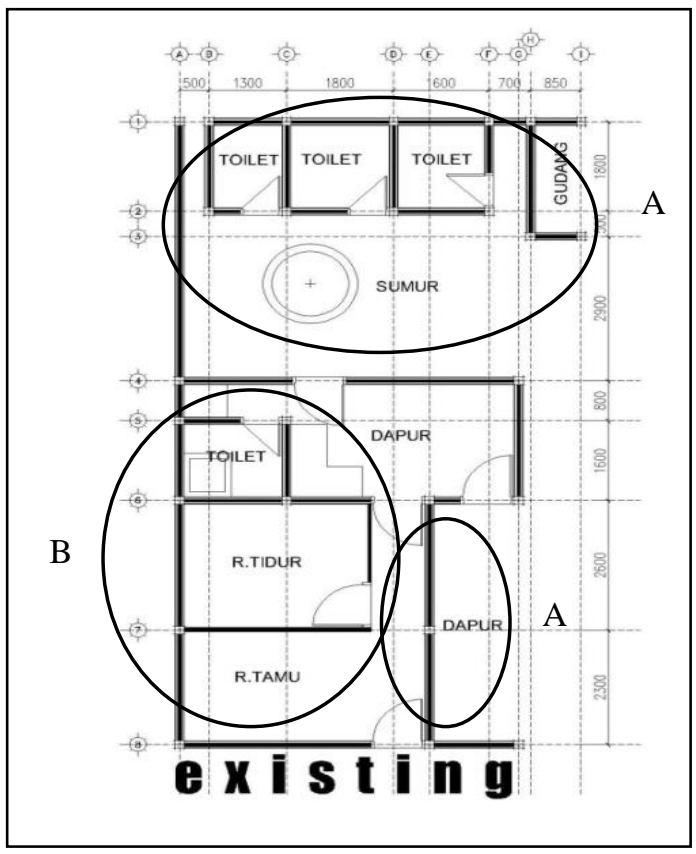

Gambar 6. Pola Pembagian Area Rumah Tinggal dan Fasilitas Bersama Keterangan: A. Fasilitas Bersama, B Rumah Inti 


\section{PENGEMBANGAN RUMAH TINGGAL}

\section{Teori Perubahan Rumah}

Pada saat fasilitas pada rumah tidak dapat mewadahi kebutuhan penghuni maka pengembangan rumah menjadi sebuah alternatif. Pengembangan rumah akan menghasilkan perubahan bentuk. Jika perubahan bentuk berkembang dengan perubahan dimensi, pengurangan atau penambahan, maka setiap unsur perubahan dapat terjadi pada beberapa susunan bentuk atau yang di sebut dengan konfigurasi bentuk [3].

Menurut Habraken, ada tiga dasar sebagai indikasi suatu perubahan pada fisik permukiman kaitannya dengan eleman pembentuk ruang, ketiga hal tersebut meliputi:

a. Addition (penambahan), yakni penambahan elemen sehingga terjadi perubahan

b. Elimination (pengurangan/ membuang) pengurangan elemen sehingga terjadi perubahan

c. Movement (perpindahan/ pergerakan), yaitu perubahan yang disebabkan oleh perpindahan atau pergeseran elemen pembentuk ruang [4]

Menurut Rapoport (dalam Rengkung dkk, 2012) bahwa rumah merupakan gejala struktural yang bentuk dan organisasinya sangat dipengaruhi oleh lingkungan budayanya. Dalam perkembangan rumah juga dipengaruhi oleh nilai sosial budaya masyarakat pemukim, dimana rumah selain berfungsi sebagai tempat tinggal juga sebagai tempat berlangsungnya proses sosialisasi dengan warga masyarakat (Soebroto, 1983 dalam Rengkung dkk, 2012) [5]. Terkait dengan perubahan rumah maka peranan penghuni sangat menentukan dalam proses perubahannya. Pada perubahan rumah terdapat aspek yang dipertahankan yaitu jalur sirkulasi dan pemisahan ruang privat dan publik serta aspek yang berubah yaitu luasan ruang dan orientasi rumah (Amad dalam Sjaifoel Ellyta, 2008) [6]

\section{Proses Perubahan Denah}

Pengembangan rumah pada lahan magersari tidak dapat berproses secara individu namun harus mempertimbangkan juga kebutuhan komunitas Pada kasus pengembangan rumah magersari maka perubahan denah dilakukan secara menyeluruh dengan tetap menyediakan fasilitas komunal berupa km/ wc dan area jemuran. Kondisi rumah no. 3 harus mengembangkan rumah tinggal dengan kebutuhan ruang-ruang antara lain: kamar tidur utama dengan fasilitas shower, dua kamar tidur anak, ruang kerja, ruang tamu, ruang keluarga menyatu dengan ruang makan dan fasilitas servis (dapur, km/ wc, cuci dan jemur). Dengan pertimbangan fasilitas komunal maka rumah no. 3 menambah km/ wc keluarga yang dapat di akses dari luar rumah. Hal ini dimaksudkan agar fasilitas bersama tetap dipertahankan untuk melayani kebutuhan keluarga.

Pengembangan rumah tidak hanya sekedar menambah, mengurangi dan menggeser ruang tetapi juga memanfaatkan dinding bangunan lama untuk menghemat biaya pembangunan. Oleh karena itu dalam proses perancangan pengembangan rumah melalui tiga tahap yaitu:

a. Menentukan struktur dinding yang masih kuat untuk di pertahankan

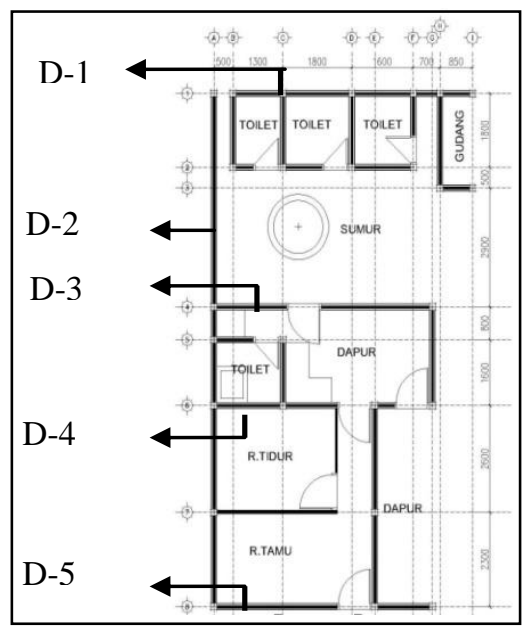

Gambar 7. Sebaran Struktur Rumah Yang Dipertahankan. Keterangan: D1: Dinding bagian belakang, D2: Dinding bagian samping, D3-D4: Dinding partisi, D5 : Dinding bagian depan

b. Menentukan jenis ruang yang di pertahankan, ditambah, dikurangi dan digeser.

Beberapa ruang yang mengalami perubahan adalah sebagai berikut:

1. Ruang yang dipertahankan hanya area sumur sebagai sumber air yang digunakan penghuni dan toilet komunal 1 (satu) unit. 


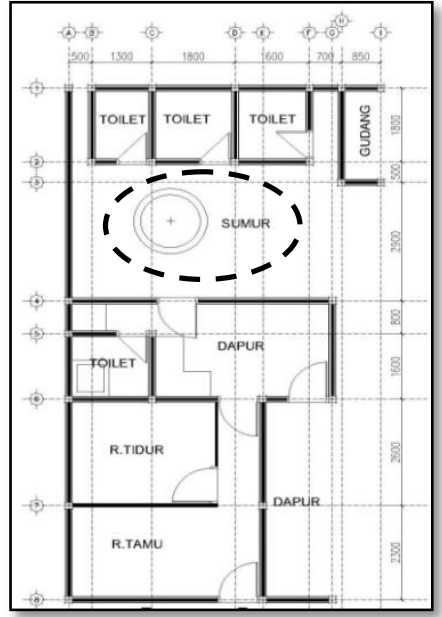

Gambar 8. Ruang Yang Dipertahankan

2. Ruang yang dikurangi adalah dapur bersama dan toilet komunal 2 (dua) unit.

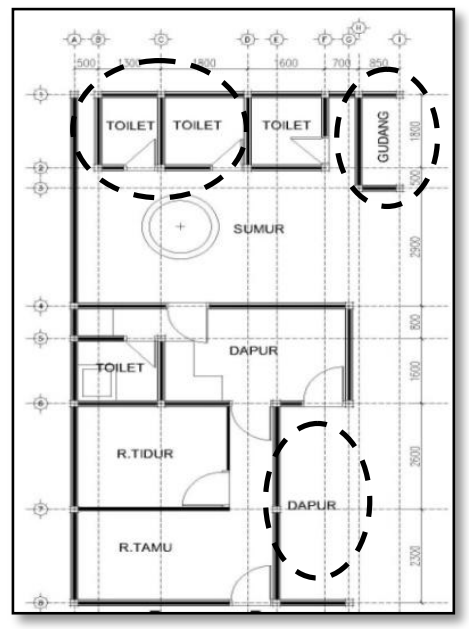

Gambar 9. Ruang Yang Dihilangkan

3. Ruang yang ditambah adalah kamar tidur yang semula hanya satu kamar tidur atas permintaan penghuni menjadi 3 (tiga) kamar tidur yaitu 1 (satu) kamar tidur utama plus toilet dan 2 (dua) kamar tidur anak. Penambahan ruang lain adalah ruang keluarga dan ruang makan yang semula tidak ada diletakkan pada bekas ruang dapur bersam dan bekas ruang cuci bersama.

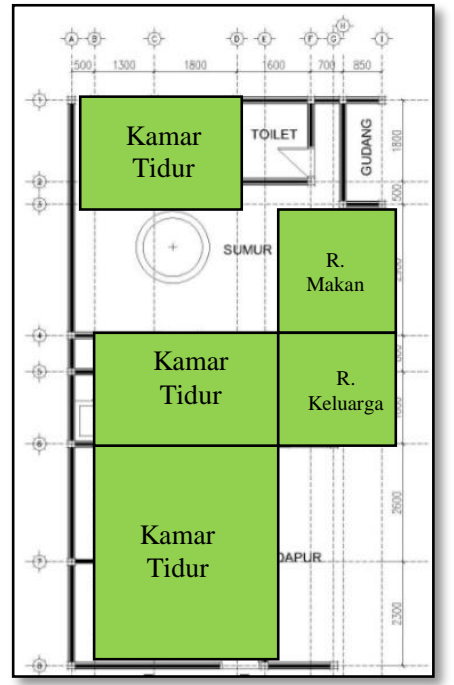

Gambar 10. Ruang Yang Ditambahkan

4. Ruang yang bergeser antara lain:

a. ruang tamu bergeser ke area bekas dapur bersama,

b. kamar tidur bergeser ke bekas ruang tamu,

c. dapur dan toilet bergeser ke area sumur

d. kamar tidur anak di tempatkan pada bekas ruang dapur dan toilet dan bekas ruang toilet komunal.

e. Ruang lain yang bergeser adalah toilet bersama 1 (satu) unit bergeser ke bekas ruang gudang.

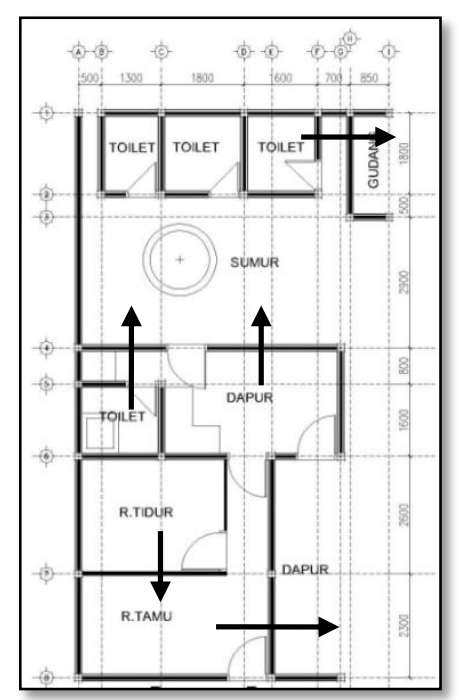

Gambar 11. Ruang Yang Digeser 


\section{Hasil Disain}

Setelah melalui proses pengembangan denah rumah magersari tersebut di atas maka dihasilkan perancangan denah sebagai berikut:

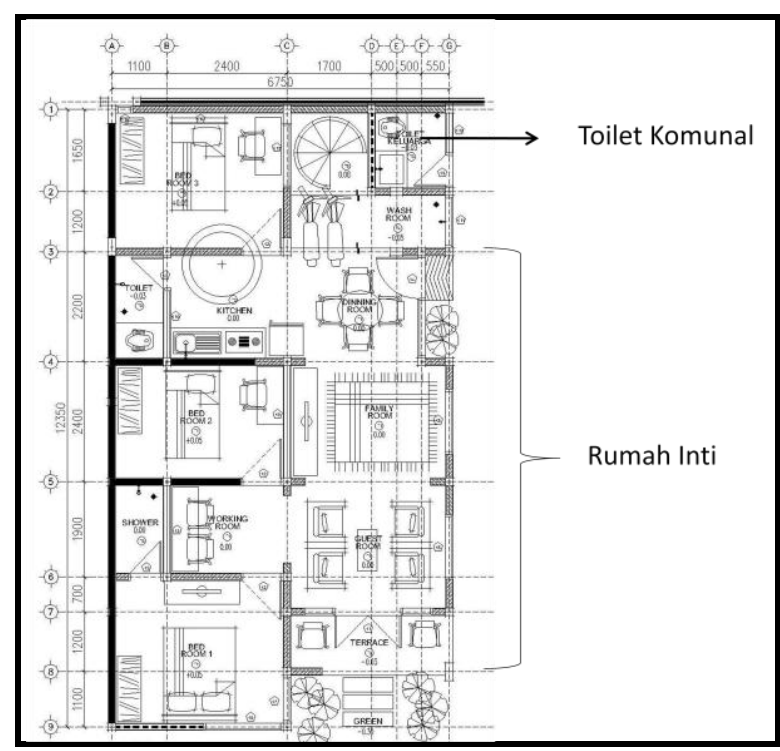

Gambar 12. Pengembangan Denah Rumah Magersari

Pada perubahan disain denah rumah magersari dihasilkan perbandingan jumlah ruang untuk rumah tinggal dan fasilitas bersama adalah 95:5. Kondisi tersebut sangat berbeda pada denah eksisting dimana porsi rumah inti dibanding fasilitas bersama adalah 40:60. Namun pada redisain denah rumah magersari telah disusun ruang-ruang sesuai zonasi publik (ruang tamu), privat (kamar tidur) dan servis (dapur, ruang makan dan toilet pribadi-komunal).

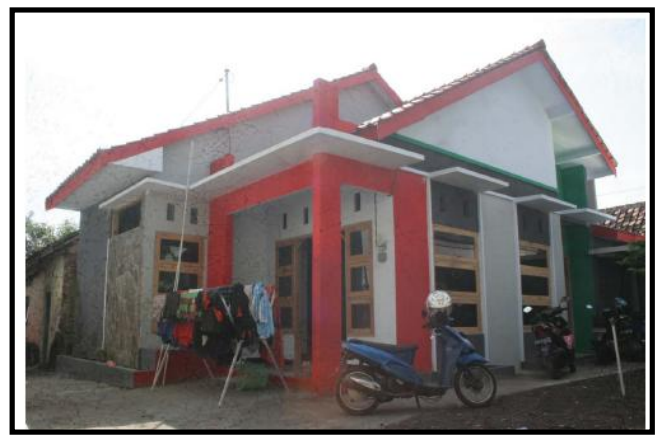

Gambar 13. Tampak Rumah Redisain

Pada disain tampak juga meniadakan pagar agar tetap terjadi interaksi antar penghuni di lingkungan magersari seperti kondisi sebelumnya. Disain minimalis pada tampak juga disesuaikan dengan rancangan rumah yang berukuran terbatas agar terjadi keseimbangan antara bangunan dan lingkungannya.

\section{KESIMPULAN DAN SARAN}

\section{Kesimpulan}

Berdasarkan hasil pembahasan yang telah dipaparkan pada bab sebelumnya, maka dapat disimpulkan beberapa bagian penting sebagai berikut:

a. Pengembangan disain rumah tinggal di lahan magersari dengan luasan terbatas menggunakan proses pengembangan rumah dengan metode penambahan, pengurangan dan pergeseran. Aspek yang dipertahankan antara lain: pemisahan ruang privat dan publik serta struktur bangunan sedangkan aspek yang berubah adalah luasan ruang.

b. Disain tampak rumah magersari menggunakan konsep minimalis agar terjadi keseimbangan skala bangunan dan lingkungan. Bangunan tanpa pagar bertujuan agar terjadi interaksi sosial antar warga sekitar.

c. Fasilitas komunal yang disediakan harus dapat diakses dengan mudah tanpa mengganggu aktifitas pada rumah inti.

\section{Saran}

a. Bagi pemilik rumah magersari perlu menjaga keberadaannya dengan pembaruan disain dan menjaga kebersihan lingkungan karena rumah magersari merupakan ciri kampung tradisonal.

b. Bagi para perancang, model disain rumah magersari masih perlu digali dengan beragam metode pengembangan disain.

\section{REFERENSI}

[1] Winarna. (2005). Magersari As An Alternative of Housing And Settlement Development Concept. Paper, Meeting and Conference. Departement of Architecture ITS

[2]http://www.google.go.id/maps/place/sukohar 远

[3] Ching, D.K, Francis. (2007). Arsitektur: Ruang, Bentuk dan Tatanan, Terjemahan Edisi Ketiga. Penerbit Erlangga.

[4] Habraken, NJ. (1982). Transformation of The Site. MASSACHUSETTS, MIT Press.

[5] Rengkung Joseph; Makarau Vicky H; Kapugu Herry. (2012). Kajian Perubahan Bentuk Arsitektur Denah Rumah Tinggal 
Kaitan Dengan Sosial Ekonomi Dan Budaya Masyarakat Pemukim Pada Perumahan Karyawan Kantor Gubernur Di Winangun Manado. Media Matrasain, vol. 9, no. 3, Jurnal Arsitektur Dan Perencanaan Kota Jurusan Arsitektur Universitas Sam Ratulangi Manado

[6] Sjaifoel, Ellyta. (2008). Kajian Perubahan Fisik Rumah Tinggal Pada Permukiman Perumnas Martubung Medan, Laporan Tesis, Sekolah Pascasarjana Universitas Sumatera Utara

[7] Azizah, Ronim. (2014). Membangun Rumah Minimalis Di Lahan Magersari. Referensi Griya Solopos, edisi Minggu, 2 November . 
